\title{
EELGRASS MAPPING WITH SENTINEL-2 AND UAV DATA IN PRINCE EDWARD ISLAND (CANADA)
}

\author{
E. Gallant ${ }^{1}$, A. LaRocque ${ }^{1, *}$, B. Leblon ${ }^{1, *}$, A. Douglas ${ }^{2}$ \\ ${ }^{1}$ Faculty of Forestry and Environmental Management, University of New Brunswick, Fredericton (NB), E3B 5A3, Canada \\ - (egallan2, larocque, bleblon)@unb.ca \\ ${ }^{2}$ Southern Gulf of St. Lawrence Coalition on Sustainability, Stratford (PEI), C1B 1L1, Canada - Coalition.sgs1@gmail.com
}

Commission III, WG III/7

KEY WORDS: Eelgrass, Sentinel-2, UAV, Micasense Red-Edge, Random Forests, Acolite, Pix4D

\begin{abstract}
:
Eelgrass (Zostera marina L.) is a marine angiosperm that grows throughout coastal regions in Atlantic Canada. Eelgrass beds provide a variety of important ecosystem services, and while it is considered an important marine species, little research has been done to understand its distribution and location within Atlantic Canada. The purpose of this study was to assess the capability of Sentinel-2 and UAV imagery to map the presence of eelgrass beds within the Souris River in Prince Edward Island. Both imageries were classified using the non-parametric Random Forests (RF) supervised classifier and the resulting classification was validated using sonar data. The Sentinel-2 classified image had a lower validation accuracy at $77.7 \%$, while the UAV classified image had a validation accuracy of $90.9 \%$. The limitations of the study and recommendations for future work are also presented.
\end{abstract}

\section{INTRODUCTION}

Eelgrass (Zostera marina L.) is an angiosperm plant that grows in brackish and salt waters of coastal areas. It is the common species in Atlantic Canada. Eelgrass beds are critical in coastal ecosystems as they provide vital ecological functions, including stabilizing sediment, providing fish habitat, influencing current dynamics, and contributing significant amounts of biomass to food webs (Heck et al., 1995). Eelgrass has the potential to serve as a sentinel of coastal environmental change associated with both natural and anthropogenic disturbances (Nahirnick et al., 2020) and has proven useful as a measure of nearshore ecosystem health. While populations are stable under pristine conditions (Ward et al., 1997), eelgrasses around the world are declining at an annual rate of $7 \%$ due to various disturbances in coastal and estuarine environments (Short, Wyllie-Echeverria, 1996). Declines in the eelgrass population have also been observed in Canada (Morris et al., 2011) and Atlantic Canada (DFO, 2009).

To properly monitor eelgrasses and to study the impacts of anthropogenic disturbances on their distribution, it is important to have a reliable method of accurately mapping the extent of eelgrass beds (Hogrefe et al., 2014). Acoustic methods can be used (Kenny et al., 2003), but they use very expensive equipment that cannot be used under certain weather conditions and they are transects that require interpolation to produce a map. The same applies to the bathymetric lidar data (Webster et al., 2015; Collins et al., 2016). By contrast, optical imagery can cover the entirety of a study area. Air photographs can be used (Mumby et al., 1997) but satellite imagery provides a larger level of coverage at a reduced cost (Dekker et al., 2006; Hossain et al., 2015). Most published studies that use optical satellite imagery have occurred only recently in Canada (O'Neill, Costa, 2013; Reshitnyk et al., 2014; Stantec, 2014; 2016; Barrell et al., 2015; Forsey et al., 2020; Leblanc et al., 2021). Temperate water poses additional challenges for mapping eelgrass compared to tropical and subtropical waters because they tend to have lower clarity, which allows for low light penetration and lower resolution between features (O’Neill, Costa, 2013; Reshitnyk et al., 2014). While satellite imagery can be a valuable tool, the availability of the imagery is limited under cloudy conditions and the imagery can be costly when imagery from commercial satellites is used. A flexible and cost-effective approach is to use unmanned aerial vehicle (UAV) images. After its development for military applications, UAV has become a popular tool for civil applications (Peasgood, Valentin, 2015). This new technology is mobile, fast, adaptable, and easy to use. UAVs can also operate at much lower altitudes, which leads to high spatial resolution images (Pajares, 2015). So far, there are only a few studies using UAV images for mapping eelgrass beds in tropical / Mediterranean and temperate environments using mostly RGB cameras (Ventura et al., 2018; Konar, Iken, 2017).

The goal of this study is to compare the potential of Sentinel-2 and UAV multispectral imagery to map eelgrass bed distribution in the Souris River (Prince Edward Island) estuary. One of the challenges of mapping eelgrass beds in this area is that it has a temperate climate where light penetration in water is generally low. In this study, both imageries will be classified with the nonparametric Random Forests (RF) supervised classifier, which does not require a normal data distribution (Breiman, 2001). RF was showed to outperform the maximum likelihood classifier in several studies (Pal, 2005; Gislason et al., 2006; Waske, Braun, 2009; Aarts et al., 2020). The classified images will then be validated by comparison with sonar data.

\section{MATERIAL AND METHODS}

\subsection{Study area}

The study area is located just above the mouth of the Souris River (Figure 1), which drains into Coville Bay, Prince Edward Island, Canada (Latitude: $46^{\circ} 21^{\prime} 57^{\prime \prime} \mathrm{N}$; Longitude: 62॰16’48” W). The Souris River has two branches that meet in Gowan Brae: the east branch flowing from Harmony Junction, and the west branch flowing from the west end of Bear River Road. From Gowan Brae, the river flows south and empties into Coville Bay, considered an inlet of the Northumberland Strait. The Souris

\footnotetext{
* Corresponding author
} 
River Watershed totals $52 \mathrm{~km}^{2}$ of streams and 5971 ha of lands, the majority of which being forested or having agricultural lands. Only a small portion of the watershed is made up of wetlands. The river is an important feature for the immediate and surrounding areas, providing significant economic, environmental, and social benefits. The watershed is also responsible for replenishing groundwater stores for drinking water. The study area was chosen for its sheltered nature, the river is separated from the bay by a causeway and a beach, providing much calmer waters for eelgrass growth. The river bottom composition is mostly sandy, with deeper channels in areas of faster water velocity.
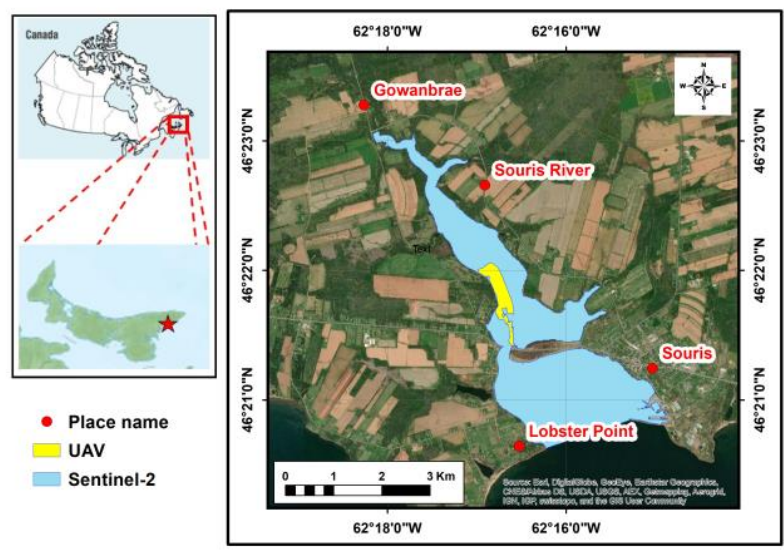

Figure 1. Location of the study area and limits of the area that was imaged by the Sentinel-2 imagery and the UAV imagery over a Google Earth image

\subsection{Image acquisition}

The UAV images were acquired using a MicaSense RedEdge narrowband camera (MicaSense Inc., Seattle, U.S.A.) mounted on a DJI Matrice 100 quadcopter (Dajiang Innovations Dajiang Baiwang Technology Co., Ltd. Shenzhen, China) (Figure 2). The images were taken on August 6th, 2019 when the eelgrass was fully developed. According to the weather measurements taken at the East Point Weather Station (Latitude: 46 $27^{\prime} 36^{\prime \prime} \mathrm{N}$; Longitude: $61^{\circ} 59^{\prime} 18^{\prime \prime} \mathrm{W}$ ), the air temperature was around $20^{\circ} \mathrm{C}$ and the relative humidity was approximately $60 \%$. Just before the imagery acquisition, the camera was calibrated by taking an image over a Spectralon panel. The MicaSense RedEdge camera has five bands described in Table 1. Both the camera and UAV were connected to mission planner software to fly at $70 \mathrm{~m}$ above the ground with a $70 \%$ overlap between adjacent images. Each image has a spatial resolution close to $7 \mathrm{~cm}$.

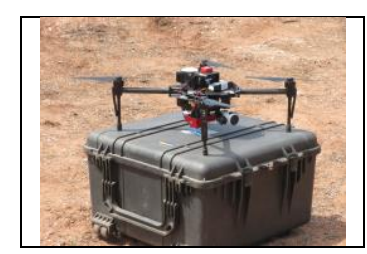

Figure 2. Picture of the DJI Matrice 100 quadcopter mounted with a Micasense RedEdge narrowband camera

The satellite image was acquired by the Multispectral Instrument (MSI) onboard the Sentinel-2 satellite from the European Space Agency (ESA). The image was resampled to a pixel resolution of $10 \mathrm{~m}$ and has a swath of $290 \mathrm{~km}$. It is projected to the ground range on the WGS84 coordinate system (European Space Agency, 2020). The Sentinel-2 image was acquired in the summer of 2019, as close as possible to the acquisition date of the UAV imagery. The characteristics of the image and related environmental conditions during image acquisition are described in Table 2.

\begin{tabular}{|c|c|c|c|}
\hline Band name & $\begin{array}{c}\text { Band range } \\
(\mathrm{nm})\end{array}$ & $\begin{array}{c}\text { Center } \\
\text { wavelength (nm) }\end{array}$ & $\begin{array}{c}\text { Bandwidth } \\
(\mathrm{nm})\end{array}$ \\
\hline Blue & $465-485$ & 475 & 20 \\
\hline Green & $550-570$ & 560 & 20 \\
\hline Red & $663-673$ & 668 & 10 \\
\hline Red edge & $712-722$ & 717 & 10 \\
\hline Near-infrared (NIR) & $820-860$ & 840 & 40 \\
\hline
\end{tabular}

Table 1. Spectral characteristics of the five MicaSense bands.

\begin{tabular}{|c|c|c|}
\hline \multicolumn{2}{|l|}{ Characteristics } & Value \\
\hline \multicolumn{2}{|c|}{ Date of acquisition } & Sept 6,2019 \\
\hline \multicolumn{2}{|c|}{ Local time of acquisition } & $12 \mathrm{~h} 16$ \\
\hline \multicolumn{2}{|c|}{ Sun zenith angle $\left({ }^{\circ}\right)$} & 41.36 \\
\hline \multicolumn{2}{|c|}{ Sun azimuth angle with respect to the North $\left({ }^{\circ}\right)$} & 161.97 \\
\hline \multicolumn{2}{|c|}{ Angle of view relative to the nadir $\left({ }^{\circ}\right)$} & 20.6 \\
\hline \multicolumn{2}{|c|}{ Resolution at nadir, after resampling $(\mathrm{m})$} & 10 \\
\hline \multicolumn{2}{|c|}{ Swath width from nadir $(\mathrm{km})$} & 290 \\
\hline \multicolumn{2}{|c|}{ Radiometric resolution (bits/pixel) } & 12 \\
\hline \multirow{11}{*}{$\begin{array}{l}\text { Band range } \\
(\mathrm{nm})\end{array}$} & Coastal & $430-457$ \\
\hline & Blue & $448-546$ \\
\hline & Red & $538-583$ \\
\hline & Green & $646-684$ \\
\hline & Red edge 1 & $694-713$ \\
\hline & Red edge 2 & $731-749$ \\
\hline & Red edge 3 & $769-797$ \\
\hline & Near-infrared (NIR) & $763-908$ \\
\hline & Red edge 4 & $848-881$ \\
\hline & SWIR 1 & $932-958$ \\
\hline & SWIR 2 & $1336-1411$ \\
\hline \multicolumn{2}{|l|}{ Tide $(\mathrm{m})^{(1)}$} & 1.0 \\
\hline \multicolumn{2}{|c|}{ Wind speed $(\mathrm{km} / \mathrm{h})^{(2)}$} & 13 \\
\hline \multicolumn{2}{|c|}{ Wind direction $\left({ }^{\circ}\right)^{(2)}$} & 320 \\
\hline \multicolumn{2}{|c|}{ Air temperature $\left({ }^{\circ} \mathrm{C}\right)^{(2)}$} & 17.4 \\
\hline
\end{tabular}

(1) Source: Souris tidal station (\#1650); (2) Charlottetown Airport station (WMO 71706)

Table 2. Characteristics of the Sentinel-2 image used in this study and related environmental conditions during the image acquisition.

\subsection{Field data}

103 GPS pictures were taken with a GoPro camera, at the same time as the UAV image acquisition to ground-truth the bottom composition within the study area. A sample of the picture for each class is provided in Figure 3. These photos were used to help delineate all the training areas over both the Sentinel-2 and UAV images. A sonar track was also acquired with a Biosonics MX Aquatic Habitat Echosounder (Biosonics Inc, Seattle, U.S.A.). Random points selected from the sonar track were used as validation points for both the Sentinel-2 and UAV classified images.

\subsection{Pre-Classification Image Processing}

Figure 4 presents a flowchart describing the method used to process both the Sentinel-2 and UAV images. The individual UAV images corresponding to the same band were first mosaicked together with the Pix4Dmapper (Pix4D, Lausanne, Switzerland) software. The template used for the mosaicking was Advanced Multispectral under the advanced category in the processing options. Different settings were attempted to create 
the best mosaic, and the final processing options used were as follows. For the initial processing, the key points image scale, which defines the image size from which the points are extracted compared to the size of the image, was set to full. For the point cloud and mesh, the point cloud densification was set to one, which indicates that the whole images were used to compute additional points. The point density was set to high with a minimum match of 2 .

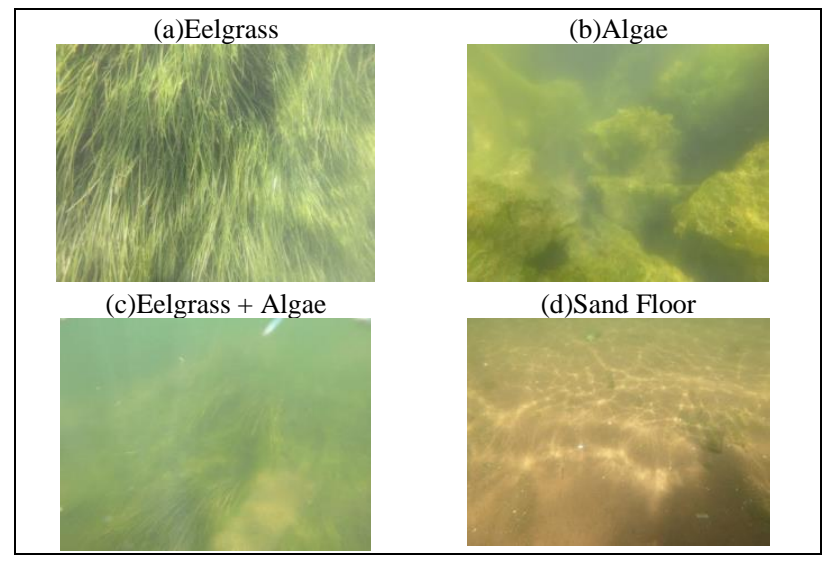

Figure 3. Ground pictures acquired with a GoPro camera for the following classes: a) eelgrass, b) algae, c) eelgrass and algae, and d) sand floor.

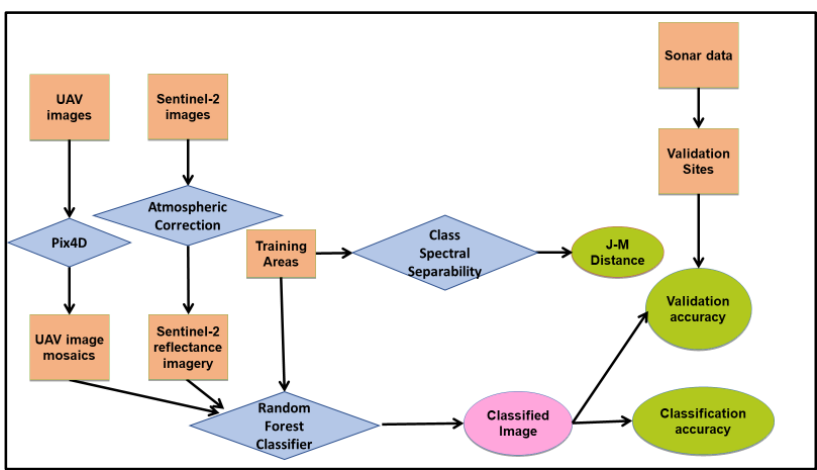

Figure 4. Flowchart presenting the methodology used for processing both the Sentinel-2 and UAV images.

The "Classify point cloud" option was selected. Under the 3D textured mesh tab, the custom option was selected, with a maximum octree depth of 8 and a texture size of $16384 \times 16384$. The decimation criterion was set to quantitative to allow identifying the maximum number of triangles as 5000000. The "use color balancing for texture" box was selected. For the DSM, the Orthomosaic, and the Index settings, the resolution was set to automatic and the DSM filters for noise filtering and surface smoothing were selected. Finally, the orthomosaic was outputted in GeoTiff file format. The mosaics were then calibrated in reflectance for each band in Pix4Dmapper, using the Spectralon reflectance panel images taken on the day of acquisition.

For the Sentinel-2 image, the atmospheric correction was performed in Acolite, free software developed by the Royal Belgian Institute of Natural Sciences, which allows a simple and fast image processing for coastal and inland water applications (Vanhellemont, 2019). Acolite uses a "dark spectrum fitting" (DSF) approach to perform atmospheric corrections, which has shown acceptable results when applied to multispectral imagery [Pereira et al., 2019; Vanhellemont, 2019; Warren et al., 2019). The DSF uses one or more dark targets in the (sub)scene to construct a "dark spectrum" which is used to estimate the atmospheric path reflectance according to an aerosol look-up table (LUT). The look-up table contains the atmospheric path reflectance $\left(\rho_{\text {path }}\right)$, the two-way diffuse atmospheric transmittance $\left(t_{d w}\right)$, the spherical albedo of the atmosphere $\left(s_{a}\right)$, and the total optical thickness of the atmosphere $\left(\tau_{t}\right)$ and is based on the $6 \mathrm{~S}$ radiative transfer model (Kotchenova et al., 2006; Vanhellemont et al., 2018). These values are then linearly interpolated to the $\rho_{\text {dark }}$ to give an estimated $\tau_{\mathrm{a}}$ for each band and aerosol model. The aerosol model is selected by determining the aerosol and band combination with the lowest Root Mean Squared Difference (RMSD) between the $\rho_{\text {dark }}$ and the estimated $\rho_{\text {path. }}$ The directional surface reflectance $\left(\rho_{s}\right)$ is then computed as follows:

$$
\rho_{s}=\frac{\rho_{c}}{t_{t o t}+s_{a^{*}} \rho_{p c}}
$$

where: $t_{\text {tot }}=$ two-way total atmospheric transmittance $\mathrm{s}_{\mathrm{a}}=$ spherical albedo of the atmosphere $\rho_{\mathrm{pc}}=$ "path-corrected" reflectance which is computed by:

$$
\rho_{p c}=\frac{\rho_{t}}{t_{\text {gas }}}-\rho_{\text {path }}-\rho_{s k y}
$$

where: $\quad \mathrm{t}_{\mathrm{gas}}=$ gas transmittance $\rho_{\text {sky }}=$ estimate of the air-water interface sky reflectance

Since the DSF selects the band giving the lowest estimate of atmospheric path reflectance, pixels with severe sun glint are avoided in the $\rho$ path estimation. It is therefore necessary to remove the effects of glint from the image. The glint reflectance $\left(\rho_{g}\right)$ can be estimated by assuming zero water-leaving reflectance in a reference band. Such a reference can be the NIR band but the NIR band often has a non-zero reflectance in turbid water. Therefore, Acolite uses the Shortwave Infrared 2 (SWIR2) band to estimate $\rho_{g}$ as follows:

$$
\rho_{g}\left(\lambda_{\text {SWIR }}\right)=\rho_{s}\left(\lambda_{\text {SWIR }}\right)
$$

\subsection{Image Classification}

Before the image classification, training areas were delineated for each class over each image. For the Sentinel-2 image, 60 training areas were randomly delineated for the 5 following classes: Eelgrass, Algae, Eelgrass + Algae, Sand, and Deep Water (Table 3 , Figure 5). In each case, each training area has only a 1-pixel size given the spatial resolution of the image and the small area covered by the study.

\begin{tabular}{|c|c|}
\hline Class & Training Area \\
\hline Eelgrass & 10 \\
Algae & 6 \\
Eelgrass + Algae & 4 \\
Sand & 17 \\
Deep Water & 23 \\
\hline Total & 60 \\
\hline
\end{tabular}

Table 3. Number of training area per class for the Sentinel-2 image classification

For the UAV imagery, a total of 572 training areas were delineated for the following 5 classes: Eelgrass, Algae in Shallow Water, Algae in deep water, Sand, and Deep Water (Table 4, Figure 6). Each training area has a size of 5 by 5 pixels. 


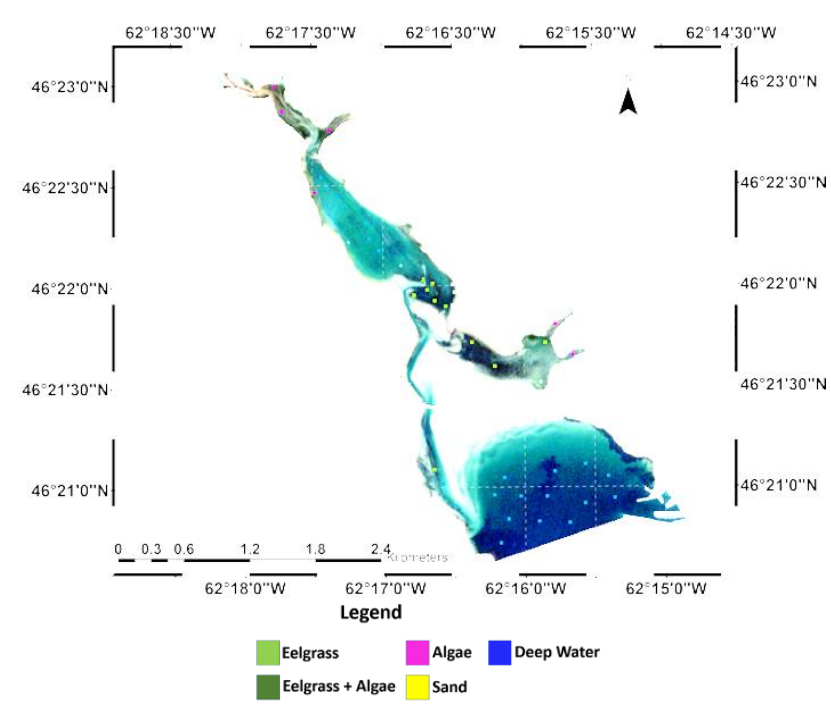

Figure 5. Distribution of training areas used in the Sentinel-2 image classification

\begin{tabular}{|c|c|}
\hline Class & Training Polygons \\
\hline Eelgrass & 88 \\
Algae in Shallow Water & 95 \\
Algae in Deep Water & 71 \\
Sand & 229 \\
Deep Water & 89 \\
\hline Total & 572 \\
\hline
\end{tabular}

Table 4. Number of training polygons per class in the Micasense UAV image

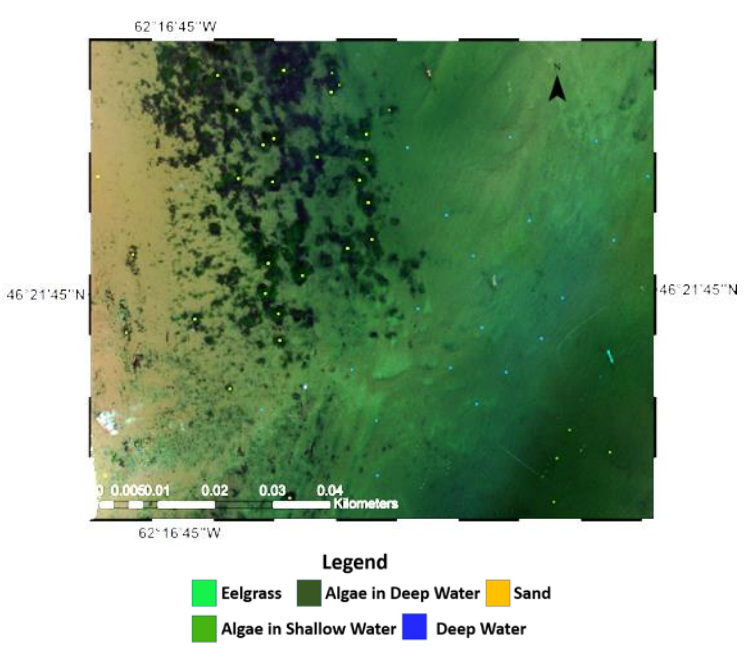

Figure 6. Sample of training areas used in the UAV Micasense image classification

The PCI Geomatica Banff ${ }^{\circledR}$ software (PCI Geomatics, Markham, Canada) was used to compute the J-M distance between class pairs. The closer the J-M distance to 2 , the better the spectral separability between the two classes is (Richards, 1994). The training areas were then used in the RF classifier, which is a nonparametric decision tree type supervised classifier. Such a classifier can handle both Gaussian and non-normally distributed data as it does not consider the data distribution parameters. RF was originally developed by Breiman and Cutler (Breiman, 2001) and implemented in R (Liaw, Wiener, 2018). The algorithm used for this study was the "all-polygon" version developed in the $\mathrm{R}$ programming language (R Development Core Team, 2013, (Byatt et al., 2018) because this version was already showed to outperform the other version (Liaw, Wiener, 2018). Indeed, it uses all the pixels within the training area polygons and thus takes into account the actual class size. The settings of the classifier were a forest of 500 independent decision trees with the default mtry variable. This variable represents the number of variables randomly sampled as candidates at each split of every node. Its default value is the square root of $p$, where $p$ is the number of variables in $x$, i.e., the matrix of predictors for the classification (Liaw, Wiener, 2018). Such default values lead to a setting that includes all input features, i.e., all pixels are randomly sampled as candidates at each split of every node. The RF classifier randomly selects two-thirds of the training data (that are not the same for each decision tree and that are referred to as "In Bag" data) to develop one decision tree. This tree is then validated using the remaining third of the training data referred to as "Out of Bag data". The process is repeated for the 500 individual decision trees and produces 500 independent classifications. These independent classifications are then combined into the final classification map (Waske, Braun, 2009). For classes with relatively limited training data, $\mathrm{RF}$ allows bootstrap aggregating of the "In Bag" data to increase the number of training pixels. Each tree is constructed using a different bootstrap sample from the original data. RF is not sensitive to noise or over-fitting and produces a "Mean Decrease Accuracy" plot that ranks the degree of usefulness of each input image in the classification (Louppe et al., 2013, Waske, Braun, 2009, Strobl et al., 2008, Gislason et al., 2006).

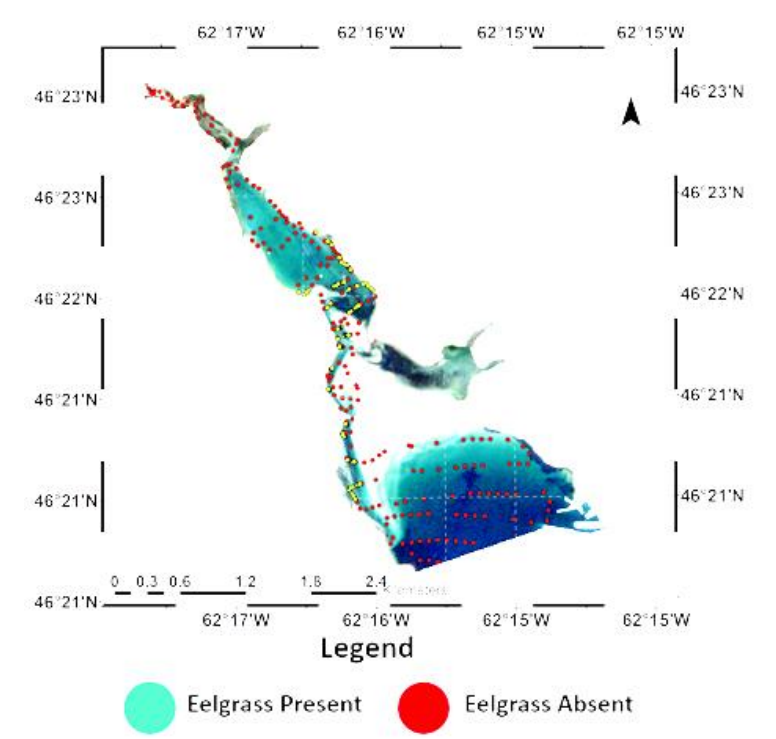

Figure 7. Distribution of the sonar points over the Sentinel-2 image

\subsection{Accuracy Assessment}

The classification accuracy was assessed first by comparing the training areas with the equivalent class in the imagery. Such comparison was performed using a "confusion matrix" or error matrix", where each cell expresses the number of pixels classified to a particular class with the class defined by the training areas (Byatt et al., 2018). The confusion matrix allows for computing the average, overall accuracies, the Kappa coefficient as well as the individual class User's and Producer's accuracies and their related errors (omission and commission), as described in (Byatt et al., 2018). However, the classification accuracy is based on training areas and does not give a good assessment of the actual map accuracy. A more robust and independent accuracy assessment is needed to compare the resulting classified image 
with an independent dataset. For such an assessment, we randomly selected 300 sonar points for the Sentinel-2 image (Figure 7), and 207 points for the UAV image (Figure 8). These validation points were categorized into two classes: Eelgrass Present and Eelgrass absent. For each sonar point, the class was extracted from the classified image using the Extract Values to Points tool of ArcMap ${ }^{\circledR}$ (ESRI, Redlands, U.S.A.). For the Sentinel-2, both the Eelgrass and Eelgrass+Algae classes were classified as "Eelgrass present", while the Sand and Deep water classes were labelled as "Eelgrass absent". For the UAV image, both the Eelgrass class was listed as "Eelgrass present, while the other classes were categorized as "Eelgrass absent". A confusion matrix and associated accuracies were then computed in R.

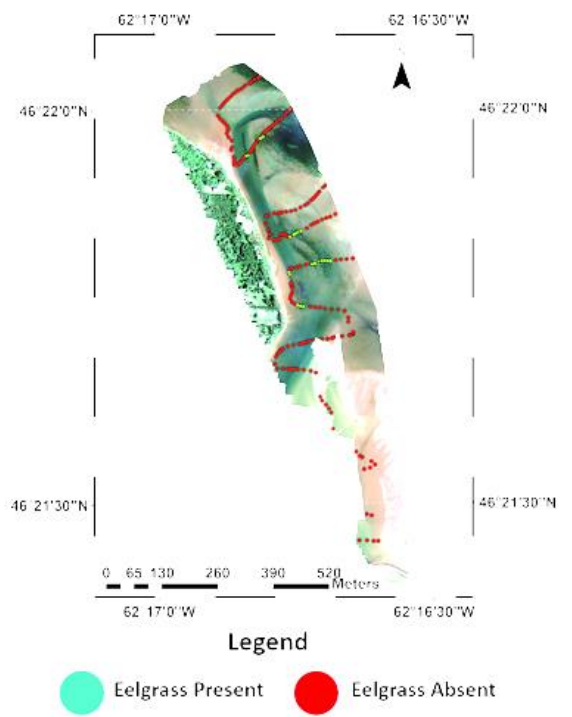

Figure 8. Distribution of the sonar points over the UAV image

\section{RESULTS AND DISCUSSION}

\subsection{Class Spectral Separability}

Tables 5 and 6 present the J-M distances between the class pairs for the Sentinel-2 image and the UAV image, respectively. The average separability for Sentinel-2 was 1.992, indicating a good spectral separability between the classes. The lowest separability was between the Eelgrass and Eelgrass+Algae classes, with a value of 1.924, which is still a good separability. Both classes include eelgrass, which may make it difficult to differentiate on the Sentinel-2 image as they correspond to similar reflectance, most notably in the RedEdge2, RedEdge3, NIR, RedEdge4, and SWIR2 bands (results not shown). The highest separability for the Sentinel-2 image was a value of 2.0, between the following class pairs: Eelgrass and Sand, Algae and Deep Water, and Sand and Deep Water. Sand is more easily distinguishable as it is a lighter color and therefore has a much higher reflectance than the other classes. This difference in reflectance is most notable in the Coastal, Blue, Green, and RedEdge1 bands (results not shown).

\begin{tabular}{|c|c|c|c|c|}
\hline Class & Eelgrass & Algae & $\begin{array}{c}\text { Eelgrass + } \\
\text { Algae }\end{array}$ & Sand \\
\hline Algae & 1.996 & & & \\
Algae + Eelgrass & 1.924 & 1.996 & & \\
Sand & 2.000 & 1.999 & 1.999 & \\
Deep Water & 1.999 & 2.000 & 1.999 & 2.000 \\
\hline
\end{tabular}

Table 5. J-M Distances computed with all 11 bands from the Sentinel-2 image
The average separability for the UAV image was 1.96 , indicating an excellent spectral separability between the classes. The lowest separability occurred between the "Algae in deep water" and "Deep water" classes with a value of 1.86 , indicating a poor separability, probably because both classes are related to deep water. This is most notable in the NIR and RedEdge bands (results not shown) The best separability occurred between the Eelgrass, the Sand, and Deep water classes, with a value of 1.999. This difference is best seen in the RedEdge, Red, and Green bands (results not shown).

\begin{tabular}{|l|c|c|c|c|}
\hline \multicolumn{1}{|c|}{ Class } & Eelgrass & $\begin{array}{c}\text { Algae } \\
\text { (shallow } \\
\text { water) }\end{array}$ & $\begin{array}{c}\text { Algae } \\
\text { (deep } \\
\text { water) }\end{array}$ & Sand \\
\hline Algae (shallow water) & 1.996 & & & \\
Algae (deep water) & 1.998 & 1.906 & & \\
Sand & 1.999 & 1.887 & 1.993 & \\
Deep Water & 1.999 & 1.982 & 1.860 & 1.940 \\
\hline
\end{tabular}

Table 6. J-M distances computed with all the 5 bands of the UAV image

\subsection{Classification}

The confusion matrices and associated classification accuracies resulting from the comparison of the training areas with the RFclassified image are presented in Table 7 in the case of the Sentinel-2 image and Table 8 in the case of the UAV image. The Sentinel-2 classification achieved an overall accuracy (OA) of $99.3 \%$, indicating an excellent classification accuracy. The lowest User's accuracy (UA) (91.67\%) and Producer's accuracy (PA) $(97.06 \%)$ corresponded to the eelgrass + algae class, probably because of confusion with the other vegetation classes. The UAV imagery classification achieved an overall accuracy of $98.91 \%$, indicating an excellent classification accuracy. The lowest User's accuracy was for the algae in shallow water class at $96.53 \%$, while the lowest Producer's accuracy was for the eelgrass class $(97.76 \%)$. Given that the eelgrass class is the class of interest for this study, this class has a User's and Producer's accuracy of $100 \%$ and $98.90 \%$ respectively with the Sentinel-2 image classification. There was almost no confusion with the other classes.

\begin{tabular}{|c|c|c|c|c|c|c|c|}
\hline Class & Eelgrass & Algae & $\begin{array}{c}\text { Eelgrass } \\
\text { +Algae }\end{array}$ & $\begin{array}{c}\text { Sand } \\
\text { Floor }\end{array}$ & $\begin{array}{c}\text { Deep } \\
\text { Water }\end{array}$ & UA (\%) & EC (\%) \\
\hline Eelgrass & $\mathbf{9 0}$ & 0 & 0 & 0 & 0 & 100 & 0.00 \\
Algae & 0 & $\mathbf{5 2}$ & 1 & 0 & 0 & 98.1 & 1.9 \\
Eelgrass + Algae & 1 & 1 & $\mathbf{3 3}$ & 1 & 0 & 91.7 & 8.3 \\
Sand Floor & 0 & 0 & 0 & $\mathbf{1 5 3}$ & 0 & 100 & 0 \\
Deep Water & 0 & 0 & 0 & 0 & $\mathbf{2 0 7}$ & 100 & 0 \\
\hline PA (\%) & 98.9 & 98.1 & 97.1 & 99.4 & 100 & \multicolumn{2}{|c|}{ Overall accuracy } \\
EO (\%) & 1.1 & 1.9 & 2.9 & 0.6 & 0 & $(\%)=99.3$ \\
\hline
\end{tabular}

(*) Bold figures indicated well-classified pixels

Table 7. Confusion matrix (in pixels) and associated accuracies when the RF classifier is applied to all the Sentinel-2 image bands.

With the UAV image classification, the User's and Producer's accuracies were $98.1 \%$ and $97.8 \%$ respectively, because of some confusion with the Algae in Shallow Water class. The resulting classified images for the Sentinel-2 (Figure 9) and UAV (Figure 10) both show that in most cases, the eelgrass beds are mostly surrounded by eelgrass + algae as well as patches of algae. Both classifications also show that most of the eelgrass beds are located in shallow water, with smaller areas of eelgrass along the edges of deep water channels. The UAV classification also produces a more detailed map due to the higher spatial resolution $(7 \mathrm{~cm})$ of the image, compared to the Sentinel-2 image, which has a spatial resolution of $10 \mathrm{~m}$. 


\begin{tabular}{|c|c|c|c|c|c|c|c|}
\hline Class & Eelgrass & $\begin{array}{c}\text { Algae } \\
\text { (shallow } \\
\text { water) }\end{array}$ & $\begin{array}{c}\text { Algae } \\
\text { (deep } \\
\text { water) }\end{array}$ & $\begin{array}{c}\text { Sand } \\
\text { Floor }\end{array}$ & $\begin{array}{c}\text { Deep } \\
\text { Water }\end{array}$ & UA (\%) & EC (\%) \\
\hline Eelgrass & $\mathbf{2 1 6 1}$ & 33 & 8 & 0 & 0 & 98.1 & 1.9 \\
Algae in Shallow Water & 43 & $\mathbf{2 2 8 4}$ & 7 & 25 & 7 & 96.5 & 3.5 \\
Algae in Deep Water & 6 & 1 & $\mathbf{1 7 4 7}$ & 0 & 10 & 99.0 & 1.0 \\
Sand Floor & 0 & 1 & 0 & $\mathbf{5 7 4 7}$ & 1 & 99.9 & 0.1 \\
Deep Water & 0 & 0 & 10 & 4 & $\mathbf{2 2 1 3}$ & 99.4 & 0.6 \\
\cline { 2 - 8 } PA (\%) & 97.8 & 98.5 & 98.6 & 99.5 & 99.2 & \multicolumn{2}{|c|}{ Overall accuracy } \\
EO (\%) & 2.2 & 1.5 & 1.4 & 0.5 & 0.8 & \multicolumn{2}{c|}{$(\%)=98.9$} \\
\hline
\end{tabular}

(*) Bold figures indicated well-classified pixels

Table 8. Confusion matrix (in pixels) and associated accuracies when the RF classifier is applied to all the UAV image bands.

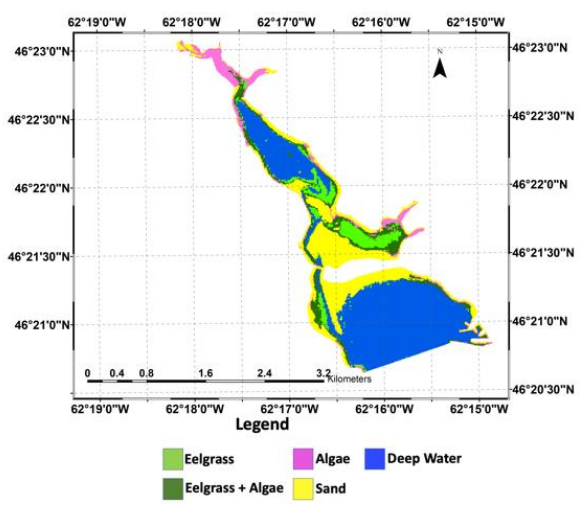

Figure 9. Classified image produced with the RF Classifier applied to all the bands of the Sentinel-2 image.

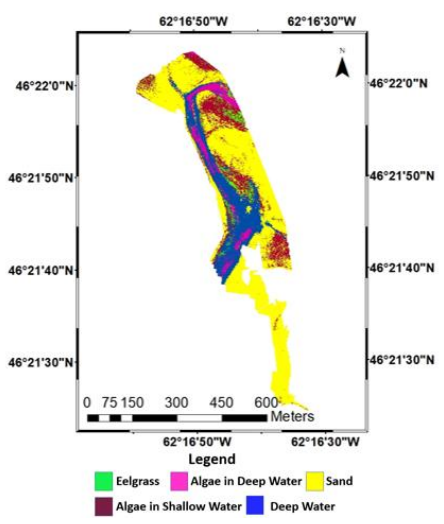

Figure 10. Classified image produced with the RF Classifier applied to all the bands of the UAV image.

The RF classifier also produces a variable importance plot, which ranks the importance of each input feature, in our case, individual band images, in the overall classification. The plot is shown in Figure 11 for the Sentinel-2 image classification and in Figure 12 for the UAV image classification. For both classifications, the Red-edge 1 band was the most important variable in the classification. The RedEdge1 band showed the most variation in reflectance values between classes for both the Sentinel-2 image (results not shown) and the UAV image (results not shown). RedEdge bands are known to be sensitive to vegetation and have been determined in previous studies to increase classification accuracy in vegetation mapping (Qiu et al., 2017). Both plots also list the Red band as the second most important band. The Red band is associated with one of the chlorophyll absorption bands, which is sensitive to the presence of green vegetation. For the Sentinel-2 classification, the SWIR2 band was determined to be the least important variable, while the Blue band was determined to be the least important for the UAV classification

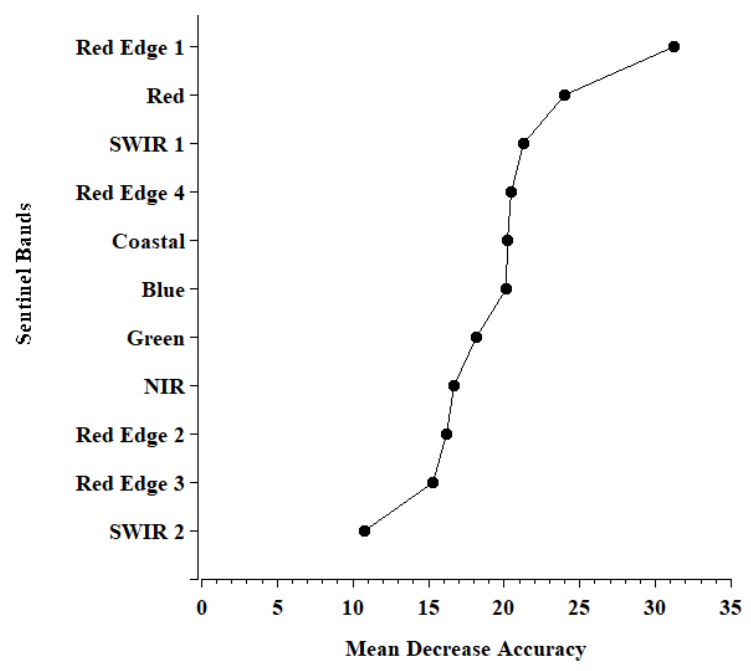

Figure 11. Variable importance plot for the Sentinel-2 image classification with RF

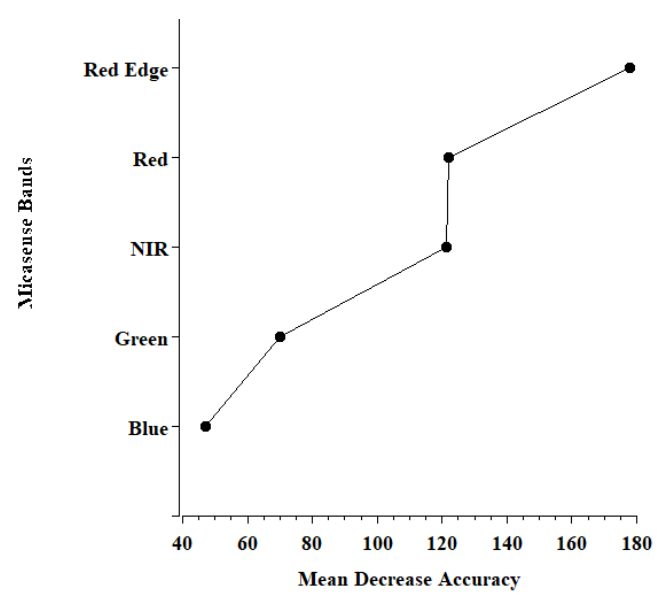

Figure 12. Variable importance plot for the UAV MicaSense image classification with RF.

\subsection{Validation}

A validation against an independent dataset is needed as the confusion matrices of Tables 7 and 8 are based on the training areas provided and do not use points that have been validated in the field. The classified images were validated by comparison to sonar data that was collected within the study area. As shown in the confusion matrices associated with the validation, we achieved an overall accuracy of $77.7 \%$ with the Sentinel-2 classified image (Table 9). For the UAV classified image, the accuracies were better, with an overall accuracy of $90.8 \%$ (Table $10)$. For the Sentinel-2 classified image, the highest Producer's $(80.9 \%)$ and User's $(84.7 \%)$ class accuracy occurred with the "eelgrass absent" class. For the "eelgrass present" class, the User's and Producer's accuracies were $65.5 \%$ and $71.3 \%$. A similar result was obtained with the UAV classified image, where the highest Producer's (93.5\%) and User's (96.1\%) class accuracy occurred for the "eelgrass absent" class. For the "eelgrass present" class, the User's and Producer's accuracies were $57.1 \%$ and $69.6 \%$. For both validations, there was a much higher proportion of sonar sites with an absence of eelgrass than there were sites with eelgrass present. Within the UAV image boundaries, only 23 of the 207 validation sites contained eelgrass, while in the Sentinel- 2 boundaries, 101 of the 300 validation sites had eelgrass present, representing approximately one-third of the ground truth points. 


\begin{tabular}{|c|c|c|c|c|}
\hline Class & $\begin{array}{c}\text { Eelgrass } \\
\text { Present }\end{array}$ & $\begin{array}{c}\text { Eelgrass } \\
\text { Absent }\end{array}$ & UA (\%) & EC (\%) \\
\hline Eelgrass Present & $\mathbf{7 2}$ & 38 & 65.5 & 34.5 \\
Eelgrass Absent & 29 & $\mathbf{1 6 1}$ & 84.7 & 15.3 \\
\hline PA (\%) & 71.3 & 80.9 & \multicolumn{2}{|c|}{ Overall accuracy } \\
EO (\%) & 28.7 & 19.1 & \multicolumn{2}{|c|}{$(\%)=77.7$} \\
\hline
\end{tabular}

(*) Bold figures indicated well-classified sonar points

Table 9. Confusion matrix (in GPS sonar points) and associated accuracies when the Sentinel-2 RF classified image is compared to the sonar data

\begin{tabular}{|c|c|c|c|c|}
\hline Class & $\begin{array}{c}\text { Eelgrass } \\
\text { Present }\end{array}$ & $\begin{array}{c}\text { Eelgrass } \\
\text { Absent }\end{array}$ & UA (\%) & EC (\%) \\
\hline Eelgrass Present & $\mathbf{1 6}$ & 12 & 57.1 & 42.9 \\
Eelgrass Absent & 7 & $\mathbf{1 7 2}$ & 96.1 & 3.9 \\
\hline PA (\%) & 69.6 & 93.5 & \multicolumn{2}{|c|}{ Overall accuracy } \\
EO (\%) & 30.4 & 6.5 & \multicolumn{2}{|c|}{$(\%)=90.8$} \\
\hline
\end{tabular}

(*) Bold figures indicated well-classified sonar points

Table 10. Confusion matrix (in sites) and associated accuracies when the UAV Micasense RF classified image is compared to the sonar data

\section{CONCLUSIONS}

Mapping of eelgrass beds is important to better understand their health, distribution, and sensitivity to anthropogenic disturbances. While aerial imagery and sonar are useful tools in detecting eelgrass beds, these options can often be expensive and require professionals to operate the equipment. This study has shown the potential of applying the Random Forests classifier to both Sentinel-2 and UAV images to produce accurate eelgrass bed distribution maps in the Souris River Estuary in Prince Edward Island. The high accuracy for both the classification $(98.9 \%)$ and validation $(90.8 \%)$ of the UAV image showed that the Micasense RedEdge narrowband camera is able of producing high spatial resolution eelgrass bed distribution maps at a reduced cost. While the Sentinel-2 image initially had a high classification overall accuracy $(99.3 \%)$, the validation overall accuracy was much lower $(77.7 \%)$. The confusion matrix revealed that for the Sentinel-2 image, the biggest source of error came from the confusion between the eelgrass+algae class and the individual eelgrass or algae classes. There was little confusion between the Eelgrass and Algae classes in the UAV image and the two classes can be identified separately. The Sentinel-2 image also had a much lower spatial resolution, meaning that the resulting map has lower spatial accuracy. The RedEdge bands were determined to be the most important variable for both classifications. Our study presents preliminary results about the test of Sentinel-2 and UAV imagery for mapping eelgrass bed distributions in an estuary in Atlantic Canada. The study only used the single band reflectance images. Further work is needed to include bathymetric ratios and vegetation index images, such as in Clyne et al. (2021). Also, there is the need to test the methodology in other estuaries of Atlantic Canada.

\section{ACKNOWLEDGMENTS}

The authors wish to acknowledge and thank Brendan Gaudet for operating the UAV, Lucas Sherry for collecting the sonar data, and Kevin Clyne for processing the sonar data. This study was funded through Environment and Climate Change Canada, Department of Fisheries and Oceans, MITACS, the CoalitionSGSL, and the University of New Brunswick via various grants and contracts awarded to Prof. Dr. B. Leblon.

\section{REFERENCES}

Aarts, L., Larocque, A., Leblon, B., Douglas, A., 2020. Use of UAV Imagery for Eelgrass Mapping in Atlantic Canada. ISPRS Annals Photogramm. Remote Sens. and Spatial Information Sciences V-3-2020, 287-292.

Barrell, J., Grant, J., Hanson, A., Mahoney, M., 2015. Evaluating the complementarity of acoustic and satellite remote sensing for seagrass landscape mapping. Int J. Remote Sens., 36(16), 40694094.

Breiman, L., 2001. Random Forests. J Mach Learn, 45(1), 5-32.

Byatt, J., LaRocque, A., Leblon, B., Harris, J., McMartin, I., 2018. Mapping surficial materials in Nunavut using RADARSAT-2 C-HH and C-HV, Landsat-8 OLI, DEM, and slope data. Can J. Remote Sens., 44(5), 491-512.

Collins, K., Webster, T., Crowell, N., McGuigan, K., MacDonald, C., 2016. Topo-bathymetric Lidar and photographic survey of various bays located in NB, NS, and PEI. Technical Report, Applied Geomatics Research Group, NSCC, Middleton (NS), pp. 1-49

Clyne, K., LaRocque, A., Leblon, B., Costa, M., Leblanc, M.L., Rabbitskin, E., Dunn, M., 2021. Use of Landsat-8 OLI imagery and local indigenous knowledge for eelgrass mapping in Eeyou Istchee, Proc. XXIV th ISPRS E-Congress, ISPRS Annals Photogram., Remote Sens. Spatial Info. Sci. (accepted)

Dekker, A., Brando, V., Anstee, J., Fyfe, S., Malthus, T., Karpouzli, E., 2006. Remote sensing of seagrass ecosystems: use of spaceborne and airborne sensors, 347-359. In Larkum, A.W.D., Orth, R.J., Duarte, C.M. (Eds). Seagrasses: Biology, Ecology, and Conservation. Springer, ISBN-10 1-4020-2983-7.

DFO (Department of Fisheries and Oceans) 2009. Does eelgrass (Zostera marina L.) meet the criteria as an ecologically significant species? DFO Canadian Science Advisory Secretariat, Research Document $\mathrm{n}^{\circ} 2009 / 018$. pp. 1-11. Retrieved from: http://waves-vagues.dfo-mpo.gc.ca/Library/337549.pdf

European Space Agency. Sentinel-2. Available online: https://sentinel.esa.int/web/sentinel/missions/sentinel-2 (accessed November 8, 2020).

Forsey, D., LaRocque, A., Leblon, B., Skinner, M., Douglas, A., 2020. Refinements in eelgrass mapping: a comparison between Random Forest and the maximum likelihood classifier. Can J. Remote Sens. 46, 491-512.

Gislason, P.O., Benediktsson, J.A., Sveinsson, J.R., 2006. Random Forests for land cover classification. Pattern Recogn. Lett. 27(4), 294-300.

Heck, K.L., Able, K.W., Roman, C.T., Fahay, M.P., 1995. Composition, abundance, biomass, and production of macrofauna in a New England estuary: Comparisons among eelgrass meadows and other nursery habitats. Estuaries, 18, 379389.

Hogrefe, K., Ward, D., Donnelly, T., Dau, N., 2014. Establishing a baseline for regional-scale monitoring of eelgrass (Zostera marina) habitat on the lower Alaska Peninsula. Remote Sens., 6(12), 12447-12477.

Hossain, M.S., Bujang, J.S., Zakaria, M.H., Hashim, M., 2015. The application of remote sensing to seagrass ecosystems: an overview and future research prospects. Int. J. Remote Sens., $36(1), 61-114$. 
Kenny, A.J, Cato, I., Desprez, M., Fader G., Schüttenhelm, R.T.E., Side, J., 2003. An overview of seabed-mapping technologies in the context of marine habitat classification, ICES J Mar Sci, 60(2), 411-418.

Konar, B., Iken, K., 2018. The use of unmanned aerial vehicle imagery in intertidal monitoring. Deep Sea Res Part II: Topical Stud Oceanogr., 147, 79-86.

Kotchenova, S., Vermote, E., Matarrese, R., Klemm, F.J., 2006. Validation of a vector version of the $6 \mathrm{~S}$ radiative transfer code for atmospheric correction of satellite data. Part I: Path Radiance. Appl. Opt., 45(26), 6762-74.

Leblanc, M.-L., LaRocque, A., Leblon, B., Hanson, A.R., Abraham, K., Humphries, M., 2021. Landsat time-series to evaluate seagrass dynamics: a case study in northeastern New Brunswick, Canada. Can J. Remote Sens. DOI: 10.1080/07038992.2021.1893672.

Liaw, A., Wiener, M., 2018. Breiman and Cutler's Random Forests for classification and regression, version 4.6-14, https://www.stat.berkeley.edu/ breiman/RandomForests/

Louppe, G., Wehenkel, L., Sutera, A., Geurt, P., 2013. Understanding variable importances in forests of randomized trees. Adv. Neural Inf Process Syst, 431-439.

Morris, C.J., Gregory, R.S., Laurel, B.J., Methven, D.A., Warren, M.A., 2011. Potential effect of eelgrass (Zostera marina) loss on nearshore Newfoundland fish communities, due to invasive green crab (Carcinus maenas). DFO Canada Science Advisory Secretariat, Research Document 2011. 2010/140, 1-17. Retrieved from: https://waves-vagues.dfo-mpo.gc.ca/Library/ 344181.pdf

Mumby, P.J., Green, E.P., Edwards, A.J., \& Clark, C.D., 1997. Measurement of seagrass standing crop using satellite and digital airborne remote sensing. Mar. Ecol. Prog. Ser., 159, 51-60.

Nahirnick, N., Costa, M., Schroeder, S., Sharma, T., 2020. Longterm eelgrass habitat change and associated human impacts on the West Coast of Canada. J. Coast. Res., 36(1), 30-40. doi: $10.2307 / 26864913$

O’Neill, J. D., Costa, M., 2013. Mapping eelgrass (Zostera marina) in the Gulf Islands National Park Reserve of Canada using high spatial resolution satellite and airborne imagery. Remote Sens. Environ., 133, 152-167.

Pajares, G., 2015. Overview and current status of remote sensing applications based on unmanned aerial vehicles (UAVs). Photogram Eng \& Remote Sens. 81(4), 281-330.

Pal, M., 2005. Random Forest classifier for remote sensing classification. Int. J. Remote Sens., 26(1), 217-222.

Peasgood, S., Valentin, M., 2015. Drones: a rising market: an industry to lift your returns. Sophic Capital, 1-11.

Qiu, S., He, B., Yin, C.., Liao, Z., 2017. Assessments of Sentinel2 vegetation red-edge spectral bands for improving land cover classification. ISPRS International Archives Photogram., Remote Sens. and Spatial Inf. Sciences, XLII-2/W7. 871-874.

R Development Core Team, 2016. R: A language and environment for statistical computing. $\mathrm{R}$ Foundation for Statistical Computing, Vienna, Austria. Retrieved from: http://www.R-project.org/.
Reshitnyk, L., Costa, M., Robinson, C., Dearden, P., 2014. Evaluation of WorldView-2 and acoustic remote sensing for mapping benthic habitats in temperate coastal Pacific waters. Remote Sens Environ, 153, 7-23.

Richards, J.A., Jia, X., 2006. Remote sensing digital image analysis: an introduction. Springer. New York. ISBN 978-3-64230062-2.

Short, F., Wyllie-Echeverria, S., 1996. Natural and humaninduced disturbance of seagrasses. Env. Conservation, 23(1), 17 27.

Stantec, 2014. Remote sensing of eelgrass at Tabusintac (NB), Final Report for Public Works and Government Services Canada, Moncton (NB), Stantec Consulting Ltd., Dartmouth, Nova Scotia. pp. 1-24.

Stantec, 2016. Accuracy assessment of remote sensing methodologies for Tabusintac Bay, New Brunswick. Report for the Canadian Wildlife Service, Environment Canada, Sackville (NB), Stantec Consulting Ltd, Dartmouth, Nova Scotia. Final Report \# 121413924, pp. 1-46

Strobl, C., Boulesteix, A.L., Kneib, T., Augustin, T., Zeileis, A., 2008. Conditional variable importance for Random Forests. $B M C$ Bioinfor, 9, 307.

Vanhellemont, Q., 2019. Adaptation of the Dark Spectrum Fitting atmospheric correction for aquatic applications of the Landsat and Sentinel-2 archives. Remote Sens. Environ, 225, 175-192.

Vanhellemont, Q., Ruddick, K., 2018. Atmospheric correction of meter-scale optical satellite data for inland and coastal water applications. Remote Sens. Environ., 216, 586-597.

Ventura, D., Bonifazi, A., Gravina, M.F., Belluscio, A., Ardizzone, G., 2018. Mapping and classification of ecologically sensitive marine habitats using Unmanned Aerial Vehicle (UAV) imagery and object-based image analysis (OBIA). Remote Sens., 10(9), 1331.

Ward, D.H., Markon, C.J., Douglas, D.C., 1997. Distribution and stability of eelgrass beds at Izembek Lagoon, Alaska. Aquatic Bot., 58, (3-4), 229-240.

Warren, M.A., Simis, S.G.H., Martinez-Vicente, V., Poser, K., Bresciani, M., Alikas, K., Spyrakos, E., Giardino, C., Ansper, A., 2019. Assessment of atmospheric correction algorithms for the Sentinel-2A MultiSpectral Imager over coastal and inland waters. Remote Sens. Environ., 225, 267-289.

Waske, B., Braun, M., 2009. Classifier ensembles for land cover mapping using multitemporal SAR imagery. ISPRS $J$ Photogramm, 64 (5), 450-457.

Webster, T., McGuigan, K., Crowell, N., Collins, K., MacDonald, C., 2015. Tabusintac 2014 topo-bathymetric Lidar and eelgrass mapping report. Technical report, Applied Geomatics Research Group, NSCC, Middleton (NS). pp 1-41

Revised April 2021 